This is a self-archived version of an original article. This version may differ from the original in pagination and typographic details. Author(s): Vähäsantanen, Katja; Räikkönen, Eija; Paloniemi, Susanna; Hökkä, Päivi;

Title: A Novel Instrument to Measure the Multidimensional Structure of Professional Agency

Year: 2019

Version: Accepted version (Final draft)

Copyright: @ S Springer Nature B.V. 2018

Rights: In Copyright

Rights url: http://rightsstatements.org/page/InC/1.0/?language=en

Please cite the original version:

Vähäsantanen, K., Räikkönen, E., Paloniemi, S., Hökkä, P., \& Eteläpelto, A. (2019). A Novel Instrument to Measure the Multidimensional Structure of Professional Agency. Vocations and Learning, 12(2), 267-295. https://doi.org/10.1007/s12186-018-9210-6 


\title{
A novel instrument to measure the multidimensional structure of professional
} agency

Katja Vähäsantanen ${ }^{\mathrm{a}}$, Eija Räikkönen ${ }^{\mathrm{b}}$, Susanna Paloniemi ${ }^{\mathrm{a}}$, Päivi Hökkäa \& Anneli Eteläpelto $^{\mathrm{a}}$

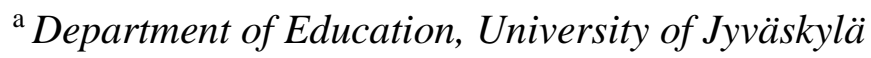

${ }^{\mathrm{b}}$ Faculty of Education and Psychology, University of Jyväskylä

\begin{abstract}
This study aimed to construct and validate a quantitative measurement instrument to determine the structure of professional agency in working life. Empirical data $(N=589)$ were collected via a web-based, theoretically informed questionnaire, within the professional domains of education, healthcare, rescue services, and information technology. The questionnaire items incorporated theoretically based dimensions of professional agency. The structure of professional agency was initially analysed via exploratory factor analysis.

Thereafter, using exploratory structural equation modelling, the structure of professional agency was investigated with a view to confirmation and validation. The results indicated that the structure of professional agency included three dimensions: Influencing at Work, Developing Work Practices, and Negotiating Professional Identity. These dimensions appeared to be separate from but closely linked to other work-related constructs, notably Learning at Work and Emotionally Meaningful Work. The study enriches current theory on professional agency by shedding light on its multidimensional structure. In presenting an instrument for measuring professional agency, the study can benefit scholars and work organisations with an interest in researching and fostering professional agency in various work and educational contexts.
\end{abstract}

Keywords: professional agency; learning at work; professional identity; measurement 


\section{Introduction}

In recent years there has been growing theoretical discussion and empirical investigation of agency in a variety of professional contexts (Eteläpelto et al. 2013; Goller and Paloniemi, 2017; Haapasaari et al. 2016; Philpott and Oates 2017; Toom et al. 2015). As a result, agency has become one of the main concepts applied to the work of professionals. In a review article, Tynjälä (2013) has further noted the salience of professional agency in the domain of workplace learning. Other scholars have also found the enactment of professional agency to be important for individual learning and for organisational development (Billett 2011; Harteis and Goller 2014; Hodkinson et al. 2008; Hökkä et al. 2008; Imants et al. 2013; Lukic et al. 2013; Vähäsantanen et al. 2017a). There are thus good grounds for focusing on professional agency in efforts to elaborate and advance the development of individual employees and work organisations. Professional agency has also been found to be connected to other work-related phenomena. It is a notable factor in professionals' creativity (Collin et al. 2017), and for their professional identity negotiations, meaningful work, and wellbeing (Kira and Balkin 2014; Pyhältö et al. 2015; Vähäsantanen and Eteläpelto 2011, 2015).

Despite a broadly shared understanding of the importance of professional agency in working life, professional agency has many differing conceptualisations. It is mostly understood as intentional actions, capabilities and dispositions, and participation; or alternatively, in terms of making choices and decisions, and influencing work-related matters, such as work practices, professional identities, or careers (see Eteläpelto et al. 2013; Harteis and Goller 2014; Toom et al. 2015). So far, perspectives on professional agency have often appeared to be one-dimensional, with investigations focusing on a single point of view. These investigations have also been based almost entirely on qualitative research. Only a few recent studies have investigated agency in working life and education via quantitative measurements (Goller 2017; Pyhältö et al. 2015), although many scholars have pointed to a need to develop 
such measurements (see Damsa et al. 2017; Harteis and Goller 2014). Moreover, the quantitative measurements conducted so far appear to be limited in scope, since in addressing agency in work and work environments they have failed to take account of professional identity.

Overall, there seems to be a lack of any comprehensive yet concise theoretical understanding of professional agency; nor has there been any rigorous quantitative instrument for measuring the multidimensional structure of agency in work contexts. The present study, conducted within Finnish working life, sought to fill this gap by constructing and validating a quantitative measurement instrument aimed at determining the structure of professional agency.

Below, we clarify the conceptualisation of professional agency. The study presented here is largely based on our own theoretical considerations and long-term qualitative studies, which have followed a subject-centred sociocultural approach (Eteläpelto et al. 2013, 2014). This approach views professional agency as primarily an action-based phenomenon, oriented and enacted towards both professional identity and work. It also emphasises professional agency as intertwined with sociocultural conditions, and with the backgrounds of the individuals concerned. In this regard, the approach suggests that professional agency cannot be divorced from social affordances, to the extent that one might view the individual alone as the starting point for an action.

In seeking to determine the structure of professional agency, we have also utilised (in addition to research and theory within a subject-centred sociocultural approach) conceptualisations by a number of scholars in the field. Here it should be noted that one can undoubtedly see connections between professional agency and other work-related constructs, such as proactivity at work and job crafting (Goller and Harteis 2017; Goller and Paloniemi 2017). Nevertheless, in formulating the initial dimensions of professional agency, we did not 
utilise the literature on these other constructs, since we wished to engage with literature that explicitly addresses and conceptualises professional agency. In this study, we have drawn notably on research from the domains of workplace learning and education, since it is within these domains that professional agency is principally conceptualised and explored. However, we do not view professional agency as a construct specific only to (for example) workplace learning; thus, our aim has been to develop an instrument that will be applicable to different professional domains and contexts. In the conceptual section below, we also elaborate learning at work, and emotionally meaningful work. These phenomena are assumed to be distinct, but closely related to professional agency, and were therefore included in the validation process undertaken in this study.

Overall, we see this study as enriching theory on professional agency by elaborating its multidimensional structure. In practical terms, it also provides a quantitative measurement instrument for researching professional agency in a variety of work and educational contexts. We anticipate that the instrument will be useful for work organisations seeking to gain information on professionals' opportunities to enact their agency, permitting them to focus support on particular dimensions in developmental work.

\section{Conceptual framework}

\section{The conceptualisation of professional agency}

Agency has been conceptualised in various ways in studies on education and working life. Some scholars have conceptualised (professional) agency as a competence, ability, capacity, or disposition that directs individuals' intentional choices and actions (e.g. Goller 2017; Goller and Harteis 2017). Although agency can be seen as a fundamental characteristic of individuals, it is often analysed in terms of actions rather than traits, properties, or capabilities (Haapasaari et al. 2016; Paloniemi and Goller 2017). Here, too, we adopt an understanding of 
professional agency as primarily an action-based phenomenon. In other words, we see professional agency as manifested in actions, and as referring notably to influencing, making choices and decisions, and taking stances at work (Eteläpelto et al. 2014). However, it should be noted that professional agency cannot always be seen unambiguously as actions, and that its conceptualisations can cover also the affordances of the workplace for the enactment of agency (see below).

Current literature has argued that for individuals, professional agency is focused on work and on the professional self (Eteläpelto et al. 2013; Harteis and Goller 2014). This implies that professional agency can be understood as oriented and enacted towards the environments, conditions, and practices of one's work, and further, towards one's professional identity and career. Viewed in this manner, professional agency encompasses the notion that professionals exert influence, make choices and decisions, and engage in negotiations regarding work, and the professional self. In the present study, on the basis of previous research, we assumed that these two main categories encompass six potential dimensions of professional agency, as follows.

(i) Decision Making at Work. In the literature, professional agency has to a large extent been conceptualised as enacted through making decisions that cover both individual work and shared work-related matters (Billett 2008; Ketelaar et al. 2012; Priestley et al. 2012; Vähäsantanen et al. 2008; Vähäsantanen et al. 2009). Thus, decisions concerning work refer, for example, to the ways of working, the contents of the work, the limits to work, shared work practices and cultures, the resources used in the work, and reforms in work organisations. Through making decisions at work, professionals are able to influence their work. It has also been found that agency - conceived as making decisions regarding both individual and collective work practices - plays a role in individual and organisational learning (Hökkä et al. 2008; Lukic et al. 2013; Ylén 2017). 
(ii) Being Heard at Work. In the current literature, professional agency also refers to the notion that individuals are significant actors in social relationships (Lipponen and Kumpulainen 2011; Pyhältö et al. 2012; Vähäsantanen and Eteläpelto 2011). In this case, agency covers the presentation of ideas that are truly heard and recognised. This could include expressing opinions and taking stances concerning both individual and shared work practices. To support the development of work organisations, there is a need to take into account professionals' opinions and ideas (Alasoini 2011). As a consequence, professionals will be able to exert a meaningful influence on their individual and shared work practices.

(iii) Participation in Shared Work Practices. Agency has been conceptualised as participation in or engagement with work activities. Many scholars have emphasised the importance of participation, seeing it as inseparably connected with learning (e.g. Lave 1993). Moreover, according to Smith (2012), employees negotiate their participation in the cultural practices that constitute their work and learning. Thus, working and learning are shaped by how employees choose to participate in interactions and practices at work. Individual agency, in the form of participatory action, can take the form of making comments and bringing up one's own opinions in the work community, or of collaborating and participating in the developmental actions of the organisation (Billett 2004; Hökkä et al. 2010, 2012; Valleala et al. 2015). Overall, it appears that the opportunities provided by the workplace are crucial for learning - as are also the ways in which individuals choose to engage with these opportunities.

(iv) Transforming Work Practices. Professional agency has further been understood as linked to the transformation of work practices (Billett 2008, 2011). In this case the agency in question is often termed transformative agency (Virkkunen 2006), and is understood as a condition for development. It manifests itself, for example, through activities that involve questioning and problematising the course of activities at work, or more proactively, through 
creating new ideas and making practical suggestions for transforming work practices (see also Collin et al. 2015; Harteis and Goller 2014; Vähäsantanen et al. 2009). This kind of active, change-oriented agency has been found to be critical for initiating and implementing innovations. Transformative agency has been the main focus in many recent activitytheoretical studies (e.g. Haapasaari et al. 2016), with agency being regarded as a quality of expansive learning. Via an emphasis on the transformation of work practices, it has also been suggested that professional agency should be understood as trying out new things at work (Billett 2011; Harteis and Goller 2014; Ylén 2017).

(v) Negotiating Professional Identity. Professional identity denotes professionals' goals and interests and their ethical principles and values at their work; it also refers to their perceptions of their relations with the work, and of their future prospects at work (Brown et al. 2007; Vähäsantanen and Eteläpelto 2011). It has been found that professional identity is reciprocally related to professional agency via two routes. On the one hand, professional agency is understood as decisions and efforts to work in a way that corresponds to one's own professional identity, plus the activities springing from such decisions (Toom et al. 2015; Vähäsantanen et al. 2008). Professionals who have a sense of their own professional agency feel in control of the choices they make, viewing these choices as based upon their goals and interests (Ketelaar et al. 2012). On the other hand, agency refers to activities via which one (trans)forms an understanding of who one is as a professional (Billett 2011; Brown et al. 2007; Ruohotie-Lyhty and Moate 2016). In a context of changing work conditions, there is a special need to consider and renegotiate professional identities in relation to changed tasks.

(vi) Constructing a Professional Career. Faced with changes in working life, professionals are also expected to enact their professional agency through acting upon their career-related decisions. In this sense, professional agency can be seen as the power to shape and give direction to one's career (Harteis and Goller 2014). This kind of agency is 
manifested via a range of activities. These could involve a decision to take a new career direction and to leave the current work organisation; on the other hand, the decision might be to make a strong commitment to one's current career pattern and work (Brown 2004; Tomlinson et al. 2013; Vähäsantanen and Eteläpelto 2015).

As indicated above, we assumed (on the basis of qualitative studies and theoretical discussion) that the structure of professional agency encompasses six dimensions. However, no individual (quantitative or qualitative) investigation has so far addressed all these dimensions; nor has any research validated the structure of professional agency along these dimensions. The present study aimed to construct and validate a measurement instrument which could determine the multidimensional structure of professional agency in working life. In addition, the study aimed to explore whether a similar structure of professional agency might exist across different professional domains. Thus, in the present study, we explored the extent of structural similarity when the nature of the work varies considerably. We took the view that, despite the general tendency to see professional agency as a context and situationbased construct (e.g. Goller and Paloniemi 2017), one might go a step further and build a quantitative instrument that would be applicable in different contexts and domains - bearing in mind that there are already qualitative studies in a variety of work contexts, applicable to endeavours for developing such instruments.

\section{Professional agency in relation to other work-related phenomena}

In this study, we sought to validate the dimensions of professional agency in relation to learning at work and emotionally meaningful work, viewing these as pivotal areas of current research in working life. One of our purposes was to demonstrate that these two phenomena are distinct from professional agency. However, we also recognise that in recent discussion, professional agency has been assumed to be connected to learning at work and to emotionally 
meaningful work, insofar as the enactment of professional agency appears to enhance learning and meaningfulness at work (Eteläpelto et al. 2014; Kira and Balkin 2014; Tynjälä 2013). Thus, we also assumed a relatively strong positive association to exist between professional agency and these two constructs. However, in the absence of previous quantitative studies on the matter, no clear assumptions were made regarding the actual magnitude of these associations.

Learning at work. In current working life, which is frequently in a state of flux, employees continually need to learn new things and to develop themselves as professionals (Billett et al. 2008; Tynjälä 2013). Learning at work mostly refers to acquiring new knowledge, updating skills, and developing competencies (Eraut 2011; Harteis and Goller 2014; Tynjälä 2008, 2013). In this sense, learning leads to changes in thinking and acting, and results in enhanced work performance. It has further been found that most learning at work occurs through collaborating, engaging in interactions plus sharing competencies and experiences, reflecting, and solving problems at work (Billett 2011; Billett et al. 2008; Eraut 2011; Hökkä et al. 2008; Tynjälä 2008). This being so, learning is often embodied in collaborative activities, and within a cultural context, taking place through everyday work practices (see also Hodkinson et al. 2008; Weber 2013).

Emotionally meaningful work. Emotions have been proven to play a crucial role, for example in decision making and in making evaluative judgements at work (Barsade and Gibson 2007). Unpleasant emotions seem to narrow people's thinking to item-level details. By contrast, pleasant emotions have been shown to enhance more holistic and relational processing (e.g. Clore and Huntsinger 2007). This means that pleasant emotions are likely to enhance inspiration and creativity at work (Thrash and Elliot 2003). Pleasant emotions and inspiration are also related to meaningful work. Work is meaningful when the associations of the work are experienced cognitively and emotionally as pleasant. Vuori et al. (2012) found 
that, in particular, the sense of a worthwhile contribution emerging from the work, with associated feelings of joy and pleasure, is related to the meaningfulness of the work (see also Chalofsky 2003). It has also been suggested that an alignment between one's preferred identity and the work creates a situation in which the individual experiences work as meaningful and comfortable (Chalofsky 2003; Kira and Balkin 2014). In other words, opportunities to negotiate one's professional identity are related to meaningful work. Since meaningful work is closely related to emotions, we here use the term Emotionally Meaningful Work. Note that emotionally meaningful work is here understood as an experiential phenomenon, in the sense that it emerges from individuals' emotional experiences, and not necessarily from the objective characteristics of the work.

\section{Methods}

\section{Data collection and participants}

The data were collected via a web-based questionnaire, administered in Finland during the period 2012-2016. We obtained the data from different professional domains, seeking thus to investigate the structure of professional agency in a range of work contexts. Furthermore, we considered such variety to be highly important in terms of validating the measurement instrument.

Prior to data collection, the managers of the work organisations in question were approached, explaining the study, and seeking permission to send questionnaires to employees. Subsequently, the researchers sent emails (personally and directly) to the employees within the organisations, requesting them to respond to the questionnaire, but making it clear that participation was voluntary. Altogether, 589 participants completed the questionnaire. 
The subjects in dataset $1(n=235)$ came from the professional domains of education (a university) and healthcare (a hospital). Those in dataset $2(n=261)$ were from the rescue services. Those in dataset $3(n=93)$ were from information technology. The response rate was similar for each dataset, with a total response rate of $32 \%$. The respondent profiles (in terms of gender, age, educational level, and employment contracts) were equivalent to the general and domain-specific employee distributions in Finland (Lehto and Sutela 2014).

Considered in more detail, dataset 1 included university personnel (i.e. teachers, researchers, and administrative personnel; $n=151$ ), and hospital personnel (i.e. nurses, physicians, and administrative personnel; $n=84$ ). The majority of the respondents were women $(n=185 ; 79 \%)$, and they worked on a permanent contract $(n=152 ; 65 \%)$. The respondents' average age was 43 years $(S D=10.99$, range 22-66), and their average work experience in years with the current employer was 11 years $(S D=9.50$, range $0-39) .9 \%$ of the respondents $(n=21)$ held the official position of a supervisor (i.e. they had subordinates working under them). The educational level of the respondents was fairly high: the majority of the respondents $(n=167 ; 71 \%)$ had at least a master's degree. Three quarters of the hospital respondents $(n=63)$ held a degree from a vocational college or polytechnic, and $42 \%$ $(n=63)$ of the university respondents had a postgraduate academic degree.

Dataset 2 encompassed professionals from the rescue services $(n=261)$, such as paramedics, fire fighters, and fire officers. The majority of the respondents were male $(n=$ $241 ; 92 \%)$, and were working on permanent contracts $(n=228 ; 87 \%)$. The average age of the participants was 41 years $(S D=10.13$, range 22-62), and their average work experience in years with the current employer was 12 years $(S D=9.83$, range $0-40)$. The majority of the respondents had a degree from a vocational college or polytechnic $(n=150 ; 58 \%)$, or from a vocational school $(n=72 ; 28 \%) .34 \%$ of the respondents $(n=88)$ held the official position of a supervisor. 
Dataset 3 encompassed professionals working in information technology $(n=93)$, such as software engineers, design engineers, and research and development engineers. The majority of the respondents were male $(n=86 ; 93 \%)$, and were working on permanent contracts $(n=86 ; 93 \%)$. Their average work experience in years with the current employer was 7 years $(S D=6.54$, range $0-29)$. In terms of educational level, the majority of the respondents had a master's degree from the university $(n=39 ; 42 \%)$, or a polytechnic degree $(n=32 ; 34 \%) .8 \%$ of the respondents $(n=7)$ had subordinates working under them.

\section{The measurement instrument}

\section{Designing the measurement instrument}

At the time of setting up the study (in 2012) there were no scales or measures to investigate agency in the domain of workplace learning (although subsequently some measures have been developed: see Goller 2017). Goller's questionnaire addresses agency at work mostly in terms of personal features. Our own focus was on an instrument that would approach professional agency primarily on the level of action. Our instrument further aimed to capture how agency may be connected to both work and professional identity. Given the lack of existing measures, there were no previously validated scales that we could use for an empirical investigation, and we thus had to develop a questionnaire with relevant items. This endeavour was based on the existing literature. The questionnaire was designed primarily to tap into professionals' agency; however, it was also intended to cover phenomena closely linked to agency, such as learning at work.

The questionnaire items were constructed on the basis of studies related to the following areas: (i) exerting influence in the work and work community (e.g. Billett 2008; Ketelaar et al. 2012; Priestley et al. 2012; Vähäsantanen et al. 2008), (ii) participation in the work community and learning at work (e.g. Billett et al. 2008; Eraut 2011; Hökkä et al. 2010; 
Jääskelä and Valleala 2012; Tynjälä 2008), (iii) professional identity and career (Billett 2011; Brown 2004; Brown et al. 2007; Ketelaar et al. 2012; Vähäsantanen and Eteläpelto 2011; Vähäsantanen et al. 2008), and (iv) meaningfulness and wellbeing at work (e.g. Young and Bhaumik 2011).

The questionnaire was pilot-tested with twelve professionals working in the fields of education and healthcare. All the subjects read the instructions for the questionnaire, and were asked to consider, for each item, the response option that best applied to them. As part of the process, the subjects were asked to think aloud, and to express their opinions and comments regarding the items. They were asked whether the items were clearly formulated, whether there were omissions, or about other points that occurred to them. Following the pilot testing, some items were modified linguistically for the final questionnaire.

In the instructions for the final questionnaire, the participants were asked to indicate what they thought of the items, and to choose the response option that best applied to them. The terms work community and unit were used in the items. Before presenting the items, it was explained that the work community means 'the community consisting of co-workers that you collaborate with' (for example, in a team, or within a project), and that unit refers to 'the university department / company or hospital unit / fire station that you work in'. All the items were measured via a 5-point response scale (ranging from $1=I$ strongly disagree to $5=I$ strongly agree).

\section{Items measuring professional agency}

The questionnaire contained 22 items relating to professional agency. Table 1 presents the theoretically based dimensions of professional agency, together with the items relating to these dimensions. For the purposes of the questionnaire, the items were developed and presented in Finnish. 
----Insert Table 1 about here----

\section{Constructs used in validating the structure of professional agency}

We sought to validate the structure of professional agency in relation to two constructs that are closely related to professional agency. In the present study, these constructs were assessed via six items included in the questionnaire. Hence, Learning at Work was assessed via three items in the questionnaire, as follows: (1) We share our know-how among co-workers, (2) We develop matters together in the work community, and (3) I learn new things by collaborating with my co-workers. Emotionally Meaningful Work was also covered by three items, as follows: (1) I enjoy my work, (2) My work is meaningful, and (3) My work inspires me.

All the items were formulated on the basis of existing literature and theory. It should also be noted that the concepts alluded to were not covered comprehensively, since our aim was not to investigate them in depth, but merely to use them for the purposes of validating the structure of professional agency.

\section{Data analysis}

In study 1 , the initial factor structure of the 22 items of professional agency was examined via an exploratory factor analysis (EFA) implemented in SPSS 24. For this purpose, dataset 1 was utilised. Since the original items were somewhat skewed (Fabrigar et al. 1999), the principal axis factoring (PAF) method was used as the method of extraction in seeking to estimate the underlying factor structure, with Promax rotation applied to facilitate interpretation of the structure. To identify possible factor structures we used a combination of eigenvalues (> 1; Kaiser 1960), Cattell's (1966) scree plot, and the minimum average partial (MAP) criterion (Velicer 1976), in conjunction with the interpretability of the solutions (Gorsuch 1983), the number of items per factor, and consistency with theoretical predictions. After deciding on the 
final factor structure, composite reliabilities (Raykov 2004) were computed for each factor.

We had four objectives in Study 2. First of all, we aimed to cross-validate the factor structure of professional agency obtained in Study 1. Secondly, after deciding on the final factor structure, we assessed the reliability of the dimensions by computing the composite reliabilities (Raykov 2004) for each factor. For these purposes, we used datasets 2 and 3. Thirdly, we examined the measurement invariance of the obtained structure across datasets 2 and 3, that is, across two different work contexts. Fourthly, we examined the convergent and discriminant validity of the structure obtained in relation to Learning at Work and Emotionally Meaningful Work. Furthermore, we assessed the discriminant validity between the dimensions of professional agency. For these purposes, we utilised dataset 2 , since the items measuring Learning at Work and Emotionally Meaningful Work were included only within that dataset.

A number of considerations are worth bearing in mind here. Traditionally, these kinds of aims have been approached using confirmatory factor analysis (CFA) and structural equation modelling (SEM). However, in many instances, item-level CFAs have failed to provide clear support for instruments that had in fact been found by EFA research to have a well-established structure (see e.g. Marsh et al. 2009; Marsh et al. 2010). The problems that arise are typically associated with goodness of fit, the differentiation of factors, measurement invariance across groups or time, and differential item functioning. Marsh et al. (2010; also Marsh et al. 2009) have argued that part of the problem is linked to the unrealistic assumption of zero cross-loadings in CFA. This typically leads to inflated factor correlations that might result in biased estimates in SEMs incorporating other variables (Asparouhov and Muthén 2009; Marsh et al. 2009; Marsh et al. 2010). This issue is particularly relevant to our investigation, given that the correlation between the professional agency factors, plus support for their convergent and discriminant validity in relation to other criteria, is critical when we 
are seeking to examine the validity of the professional agency scale. Furthermore, recent studies have shown that EFA models are better at recovering true population latent correlations, and that CFA-based latent correlations can be severely inflated by the presence of a few small cross-loadings erroneously fixed at 0 (Asparouhov and Muthén 2009; Marsh et al. 2013).

Thus, it would seem that EFA models are better suited than CFA models to datadriven studies in which the selection of an optimal measurement model is guided by a priori assumptions (albeit, as in our study, with a strong foundation in theory and qualitative research). However, until recently, EFA has been lacking in the methodological advances associated with CFA (Asparouhov and Muthén, 2009; Marsh et al. 2009).

In this research, we used exploratory structural equation modelling (ESEM; Asparouhov and Muthén 2009; Marsh et al. 2009; Marsh et al. 2010), which integrates EFA within a CFA/SEM framework. Within the ESEM framework, it is possible, for example, to estimate measurement-error corrected latent variables; to compute standard errors and goodness-of-fit statistics; to compare competing models through tests of statistical significance and fit indices; to include correlated residuals; and to include both CFA and EFA factors based on the same, different, or overlapping sets of items. In addition, multiple group invariance analyses can be conducted. The main difference between ESEM and CFA is that in ESEM, loadings from all factors to all items are estimated, whereas in CFA, each item is required to load on only one factor. Further information on the ESEM method (e.g. on estimation and identification issues) can be found in the articles by Asparouhov and Muthén (2009) and Marsh et al. (2009). Furthermore, ESEM typically provides a better fit with the data than CFA, and results in factors that are less correlated, given that ESEM uses two estimates of overlap between factors (overlap in factor loadings, and correlation between 
factors). By contrast, CFA uses only the correlation between factors (Marsh et al. 2009; Marsh et al. 2010).

The measurement invariance of the ESEM model between datasets 2 and 3 was investigated via the following models, evaluated successively (Meredith 1993; see also Marsh et al. 2009; Marsh et al. 2010): (i) the configural invariance (factor loadings, intercepts, and uniquenesses, i.e. residual variances of the items, were freely estimated, with the latent variances being constrained to 1 , and the latent means constrained to 0 ); (ii) weak invariance (with loadings constrained to be the same across the datasets); (iii) strong invariance (with loadings and item intercepts constrained to be equal across datasets); (iv) strict invariance (with item uniquenesses, item intercepts, and loadings constrained to be equal across the datasets); (v) invariance of factor variances/covariances; and (vi) invariance of factor means. In each step, the preceding model served as a reference.

The discriminant validity between the dimensions of professional agency was assessed, and the convergent and discriminant validity of the structure of professional agency examined in relation to Learning at Work and Emotionally Meaningful Work. Prior to the examinations, a CFA measurement model was formed, in which the constructs Learning at Work and Emotionally Meaningful Work were set to correlate with each other. Convergent validity was examined via correlations (i.e. the three dimensions of professional agency were set to correlate with Learning at Work and Emotionally Meaningful Work). The discriminant validity was assessed by the Fornell-Larcker method (Fornell and Larcker 1981). This method requires comparison of the average variance extracted (AVE) estimate of each latent construct with the shared variance (i.e. squared correlations) between the latent construct of interest and all the other latent constructs in the estimated model. The AVE estimate is the average amount of variance that a latent construct is able to explain in the observed items to which it is theoretically related. The AVE estimate of a latent construct is computed as the average of 
the squared loadings of those items that theoretically relate to that particular latent construct. The discriminant validity can be regarded as sufficient if the latent construct's AVE is greater than the variance it shares with all the other latent constructs in the model.

All the ESEM analyses were conducted using Mplus version 7.3 (Muthén and Muthén 1998-2012). We employed an oblique geomin rotation (the default) with an epsilon value of .5 (Marsh et al. 2009; Marsh et al. 2010). The few missing values (covariance coverage 98.5$100.0 \%$ ) were assumed to be missing at random, and, since the data were not normally distributed, the robust maximum likelihood estimator (MLR) was used. The Full-InformationMaximum-Likelihood (FIML) procedure was used to account for missing data.

As in previous ESEM studies (e.g. Arens and Morin 2016; Marsh et al. 2009; Marsh et al. 2010), the assessment of fit for the ESEM models was based on multiple indicators that are established in CFA, i.e. the chi-square $\left(\chi^{2}\right)$ test, the root mean square error of approximation (RMSEA), standardised root mean square residuals (SRMR), the Tucker-Lewis Index (TLI), and the Comparative Fit Index (CFI). It is accepted that values smaller than 0.06 for RMSEA and .08 for the SRMR indicate a reasonable fit with the data (Hu and Bentler 1999; Kline 2016). The TLI and CFI vary along a 0 to 1 continuum, and values greater than 0.90 and 0.95 indicate, respectively, an acceptable and an excellent fit with the data. The significance value of the $\chi^{2}$ test should be greater than .05. However, it has been suggested (Marsh et al. 2009; Marsh et al. 2010) that fit indices which correct for parsimony (TLI and RMSEA) may be particularly important in ESEM, given the large number of estimated parameters (for example, in ESEM, the number of factor loadings is the product of the number of items times the number of factors). Despite this, it should be noted that research regarding the adequacy of these criteria for ESEM is still lacking (Arens and Morin 2016). Hence, as suggested in other ESEM studies (e.g. Arens and Morin 2016; Marsh et al. 2009; Marsh et al. 2010), we have used these criteria only as rough guidelines for facilitating model evaluation, and have 
simultaneously considered other criteria for determining the fit of our ESEM models, such as the theoretical adequacy of the model.

In comparing the models at each step of the invariance tests, the chi-square $\left(\chi^{2}\right)$ difference test (Satorra and Bentler 2001) was used. A statistically significant $\chi^{2}$ difference test denotes that the reference model (i.e. with the parameters of interest being freely estimated across datasets 2 and 3 ) fits better with the data than the constrained model (i.e. with the parameters of interest being constrained to be equal across datasets 2 and 3 ). However, the $\chi^{2}$ difference test does not accommodate the effects of model complexity; hence, the less parsimonious models in a nested sequence always fit better than a parsimonious model. This issue is particularly relevant in our study because nested ESEM models differ greatly in degrees of freedom. Relying on indices that do not adjust for parsimony may amplify the risk of capitalising on chance.

As suggested by Chen (2007) and by Cheung and Rensvold (2001), changes ( $\Delta$ ) in fit indices were more closely inspected in our study. A $\triangle \mathrm{CFI} \leq .01$, and a $\triangle \mathrm{RMSEA} \leq .015$ between a more restricted (parsimonious) model and the reference model, would indicate reasonable support for the more parsimonious model (Chen 2007; Cheung and Rensvold 2001). For indices incorporating a penalty for lack of parsimony, such as the TLI and RMSEA, it is possible for a more restrictive model to result in a better fit than would be the case for a less restricted model; thus $\Delta$ TLI should also be inspected (Marsh et al. 2005).

\section{Results}

\section{Study 1: initial factor structure of professional agency}

According to the initial EFA results, items 1.4 and 4.2 (see Table 1) had low communalities $(<.30)$, suggesting that they did not measure the factor structure well. They were therefore removed from further analysis. In addition, items 4.5, 5.1, and 6.1 were removed due to 
multicollinearity. After these modifications, we re-estimated the EFA using 17 items. The criteria for choosing the best EFA solution pointed to different solutions. Thus, the Kaiser criterion (eigenvalues $>1$ as a rule of thumb; see Figure 1a) indicated that a three-factor solution would be the best approximation with the data. By contrast, according to Cattell's scree plot test (Figure 1a), 1-3 factors should be selected, since the 'elbows' of the plot were located under two, three, and four factors. The minimum point for the MAP test was 0.0256 (see also Figure 1b), and it was obtained for both two and three factors. Thus, it seems that a 2-factor and 3-factor structure received most support. Inspection of the loading patterns of these two solutions revealed that in the 2-factor solution, items 1.1-1.3, 2.1-2.3, 5.2.-5.4, and 6.2 (see Table 1) were all collapsed into the same factor, whereas in the 3 -factor solution items 5.2-5.4 and 6.2 formed a factor of their own. Otherwise, the solutions were similar. As the 3-factor solution made more sense than the 2-factor solution from a theoretical point of view, the 3-factor solution was chosen as the final EFA solution. This solution covered $55.44 \%$ of the shared variance between the items. The correlations between the factors were: $r_{\mathrm{f} 1, \mathrm{f} 2}=0.40, r_{\mathrm{f} 1, \mathrm{f} 3}=0.59$, and $r_{\mathrm{f} 2, \mathrm{f} 3}=0.51$. Five of the 17 items cross-loaded (i.e. loading 0.32 or higher on two or more factors; Tabachnik and Fidell 2001) on two factors; these were item 1.2 (factors $3 \& 1$ ), items 2.2 and 2.3 (factors $1 \& 3$ ), item 3.4 (factors $2 \& 1$ ), and item 4.4 (factors $2 \& 3$ ). We decided not to remove these items, as we wanted to see how they would behave in our cross-validation datasets. In the cross-validation, we used ESEM, which allows cross-loadings between factors.

----Insert Figures 1a and $1 \mathrm{~b}$ about here----

The three-factor structure, percentage of variance explained by each factor, and composite reliability for each factor are presented in Table 2 . The first factor was labelled as 
Influencing at Work. It related to the original items 1.1-1.3 and 2.1-2.3. It thus involved two of the theoretically based dimensions, namely Decision Making at Work and Being Heard at Work (see Table 1). The second factor was labelled as Developing Work Practices, and it related to items 3.1-3.4, 4.1, and 4.3-4.4. Thus, the second factor combined the theoretically based dimensions of Participation in Shared Work Practices and Transformation of Work Practices. The third factor was labelled as Negotiating Professional Identity. It related to items 5.2-5.4 and item 6.2. It thus encompassed two of the theoretically based dimensions (Negotiating Professional Identity and Constructing a Professional Career). The reliabilities of the three dimensions were found to be acceptable (Table 2). Overall, the names of the factors are in line with a view of professional agency as a set of action-based phenomena. However, it should be recognised that some items denoting the first factor cover also the affordances of the workplace for the enactment of agency.

----Insert Table 2 about here----

\section{Study 2: cross-validation and group invariance of the structure of professional} agency

Descriptive statistics and Pearson correlations for the 17 items of professional agency in datasets 2 and 3 are presented in Appendix 1. Cross-validation of the structure of professional agency was conducted using these items in datasets 2 and 3. The fit of the initial ESEM model with the three factors was relatively poor: $\chi^{2}(88)=287.81, p<0.001, \mathrm{CFI}=.92$, TLI $=.87$, RMSEA $=0.08$ [90\% CI $=0.07 ; 0.09]$, SRMR $=0.04$. Modification index values (MIs) suggested several improvements to our model. However, only three of them were theoretically meaningful (belonging to the same theoretically based factor): this was observed in the residual covariances between items 3.1 and $3.2(\mathrm{MI}=47.13)$, items 2.1 and $2.2(\mathrm{MI}=$ 
28.03), and items 4.3 and 4.4. $(\mathrm{MI}=13.86)$. Other MI suggestions would have resulted in residual covariances between items that were theoretically assumed to belong to different agency factors, or else in negative residual covariances between some of the items. The latter would suggest that these kinds of items were inversely related to each other - a conclusion which is not theoretically reasonable. The three meaningful residual covariances were added to the model one by one. Our modified model fitted the data relatively well: $\chi^{2}(85)=198.67$, $p<0.001, \mathrm{CFI}=.95, \mathrm{TLI}=.92, \mathrm{RMSEA}=0.06[90 \% \mathrm{CI}=0.05 ; 0.07], \mathrm{SRMR}=0.03$. This solution was chosen as our final one, and it is presented in Table 3. All the statistically significant loadings were positive. Moreover, the residual variances of the items were statistically significant and positive. The composite reliabilities and correlations between the dimensions of professional agency are shown in Table 4. The reliabilities of the three dimensions were found to be acceptable.

----Insert Tables 3 and 4 about here----

Next, the invariance of the structure of professional agency was examined across datasets 2 and 3 . These represented professionals from two very different work contexts, namely rescue services and information technology. We found reasonable support for weak invariance; that is, the factor loadings were the same across the datasets (Table 5). Thus, the employees from the two different fields exhibited the same meaning attribution regarding the dimensions of professional agency. 
However, there was no support for complete strong invariance (i.e. equality of item intercepts and factor loadings across datasets). This suggested that one or more of the items functioned differently between the two groups of professionals (i.e. that the response style between the groups was different). Because of this, we pursued tests for partial invariance of the item intercepts. The MIs suggested that the intercepts of items 1.2, 2.3, 3.4, and 4.4 contributed most to the misfit associated with the complete invariance of the item intercepts ${ }^{1}$. These parameters were freed one at a time. After these modifications, the model fit was almost the same as after examination of weak invariance, thus supporting partial invariance of the item intercepts (Table 5). The analysis here also justified comparison of means of the factors of professional agency between the two groups of professionals. However, due to the partial invariance of the item intercepts in factors 1 and 2, only items that meet the strong invariance criteria (Factor 1: items 1.1, 1.3, 2.1, and 2.2; Factor 2: items 3.1-3.3, 4.1, and 4.3) actually contribute to the estimates of the group differences in the means of these two factors (with the computation of the means of these factors having been based only on those items that met the strong invariance criteria; see Steenkamp and Baumgartner 1999).

Strict measurement invariance (i.e. equality of item residual variances, item intercepts, and factor loadings across datasets) did not receive adequate support (Table 5). The MIs suggested that the residual variances of items $2.1(\mathrm{MI}=9.77), 1.2(\mathrm{MI}=9.63)$, and $2.3(\mathrm{MI}=$ 9.33) differed across datasets 2 and 3. After freeing the equality constraints of the aforementioned residual variances, partial invariance was obtained, suggesting that the measurement errors did not differ substantially in the two datasets, and thus enabling comparison of the manifest scores (i.e., the simple unweighted averages or sums of the items

\footnotetext{
${ }^{1}$ Four items differed across the datasets: Item 1.2 rescue services, mean $=3.44$ vs. information technology, mean $=4.02$. Item 2.3 rescue services, mean $=3.75$ vs. information technology, mean $=4.12$. Item 3.4 rescue services, mean $=3.87$ vs. information technology, mean $=3.54$. Item 4.4 rescue services, mean $=3.67$ vs. information technology, mean $=3.97$.
} 
designed to measure each factor) or factor scores. The fifth step, involving the invariance of factor variances/covariances thus received support. This is important, given that our subsequent aim was to examine the dimensions of professional agency in relation to the constructs Learning at Work and Emotionally Meaningful Work, in order to assess convergent and discriminant validity. Examination of the structure of professional agency in relation to other constructs would not be valid in the absence of invariance between the factor variances/covariances of the dimensions of professional agency (Marsh et al. 2009; Meredith 1993). At the final step, the invariance of the latent means received support. However, as noted above, the assessment of group invariance in the means of factors 1 and 2 was based on the items that met the strong invariance criteria (Factor 1: items 1.1, 1.3, 2.1, and 2.2; Factor 2: items 3.1-3.3, 4.1, and 4.3); in other words, the computation of the means of these factors was based only on those items that met the strong invariance criteria (Steenkamp and Baumgartner 1999). In factor 3, all four items $(5.2--5.4,6.2)$ met the strong invariance criteria. Hence, the assessment of group invariance in the mean of factor 3 was based on all four items (Steenkamp and Baumgartner 1999).

In addition, we explored the discriminant validity of the dimensions of professional agency. As shown in Table 4, the AVE estimates of the dimensions of professional agency were higher than the estimates of shared variance between the dimensions. Thus, the discriminant validity of the structure of professional agency could be regarded as confirmed.

Before we examined the dimensions of professional agency in relation to the constructs Learning at Work and Emotionally Meaningful Work, we checked their factorial structure and found it to be acceptable $\left(\chi^{2}(8)=7.08, p=0.53 ; \mathrm{RMSEA}=.00[90 \% \mathrm{CI}=0.00\right.$; 0.07], $\mathrm{CFI}=1.00, \mathrm{TLI}=1.01 ; \mathrm{SRMR}=.03)$. The factor loadings were relatively high, and the residual variances of the observed variables were positive and statistically significant (see Figure 2). The correlation between the factors was $0.63(p<0.001)$. 
----Insert Figure 2 about here----

As shown in Figure 2, the dimensions of professional agency were positively related to Learning at Work and Emotionally Meaningful Work. Thus, the more the participants reported that they were able to influence their work, develop their work practices, and negotiate their professional identity, the more they perceived that they learnt at work and experienced their work as emotionally meaningful. All three dimensions of professional agency were relatively strongly related to Learning at Work. In contrast, the associations between the dimensions of professional agency and Emotionally Meaningful Work varied in strength. Negotiating Professional Identity had the strongest association with Emotionally Meaningful Work, whereas Developing Work Practices had the weakest association. The results suggest that sufficient convergent validity of the dimensions of professional agency was achieved.

Table 4 presents AVE estimates of the dimensions of professional agency, Learning at Work and Emotionally Meaningful Work, plus the shared variance estimates between them. The AVE for each construct was higher than its shared variance with any other construct. In other words, the discriminant validity of the structure of professional agency could be regarded as confirmed, and the dimensions of professional agency could be regarded as distinct from Learning at Work and Emotionally Meaningful Work.

\section{Discussion and conclusions}

\section{Theoretical contribution}

Given the lack of a clear and comprehensive quantitative framework for investigating professional agency in working life contexts, this study enriches current discussion and theory 
on professional agency by revealing a multidimensional structure for it. As a main finding, the results showed a three-factor structure for professional agency. These three factors are: Influencing at Work, Developing Work Practices, and Negotiating Professional Identity. Statistical methods were used to distinguish the three dimensions empirically. Only positive, relatively low correlations between them were found. This would indicate that the different dimensions of professional agency are related, but separate from each other.

Our initial assumption was that the structure of professional agency includes six dimensions. However, we found that a three-factor model reflected our data better. In this factor model, the two initially assumed factors (Decision Making at Work and Being Heard at Work) formed one factor, which we named Influencing at Work. The factor Developing Work Practices also included two initially assumed factors (Participation in Shared Work Practices, and Transforming Work Practices). Finally, two initially assumed factors (Negotiating Professional Identity and Constructing a Professional Career) were placed within a single factor, namely Negotiating Professional Identity. Notwithstanding our original assumption, it can be suggested that the findings of this study make sense, since the current literature views some of the original theoretically based dimensions as partly overlapping. For example, it has been suggested that agency focusing on professional identity includes also actions to shape and construct one's professional career (Ruohotie-Lyhty and Moate 2016; Vähäsantanen et al. 2017a).

Since the three dimensions of professional agency were covered by 17 items, not all of our initial items $(n=22)$ were incorporated in the validated structure of professional agency. The non-inclusion of the five deleted items in the final structure can be explained in terms of two of the items having low communalities (suggesting that they did not measure the factor structure well). The other items were removed due to multicollinearity. 
The strength of the study was that it was conducted in different professional domains, and used a variety of analytical methods. The average values between the different domains were notably similar; thus only four item intercepts (1.2, 2.3, 3.4, and 4.4; see Table 1 and 3) differed across datasets 2 and 3 (obtained respectively from subjects in the rescue services and information technology). This can be seen as acceptable, since the partial invariances (i.e. differing response patterns in these items between professionals from two different work contexts) can be understood from the viewpoint of the nature of the work. One could say that creative work in the domain of information technology includes more opportunities for influencing at work and for developing work practices compared to rescue work, which requires controlled and routine-like ways of working in emergencies. Thus, these partial invariances imply that some items related to professional agency can be manifested variously in different professional domains.

Recent discussion has suggested that professional agency is closely intertwined with professionals' wellbeing, creativity, learning at work, and sense of meaningfulness at work (Eteläpelto et al. 2013; Philpott and Oates 2017; Pyhältö et al. 2015; Tynjälä 2013). This study demonstrated that the dimensions of professional agency can be seen as partly connected, but nevertheless as distinct from the constructs of Learning at Work and Emotionally Meaningful Work, even if these constructs are positively connected to the dimensions of professional agency. In particular, Emotionally Meaningful Work is closely related to the dimension of Negotiating Professional Identity. On the basis of previous discussion (Chalofsky 2003; Kira and Balkin 2014), we would explain this finding as an indication that experiences of emotional meaningfulness at work emerge from situations in which professionals can realise their professional goals and interests within the work. Vuori et al. (2012) have further noted that influencing the work content is one strategy to make work meaningful. The present study also illustrates the close favourable connection between 
Influencing at Work and Emotionally Meaningful Work. In seeking to test convergent and discriminant validity we did not utilise existing well-known validated scales. Instead we formulated items related to Learning at Work and Emotionally Meaningful Work. Such items can be seen as problematic in efforts to test validity.

\section{Limitations and implications}

The dimensions of professional agency were constructed via research data from different professional domains in Finland. Although the participants in the different datasets were representative in terms of their professions, age, gender, and working experience, all the participants were highly educated, and this could be viewed as decreasing the representativeness of the participants. Note also that although this can be seen as a limitation of our study, it can also explain three residual covariances obtained between items (items 3.1 and 3.2; items 2.1 and 2.2; items 4.3 and 4.4). These items were not removed during the analysis for two reasons. Firstly, we could not be sure of the functionality of these items in different socio-cultural contexts, and with different kinds of participants (bearing in mind that the present research was conducted in specific cultural/national contexts with highly educated professionals). Secondly, our initial ESEM model was modified by adding three covariances between residuals. All three of these made good sense, since they existed between items that were included within the same factor in our originally assumed six-factor model. In cases in which two residual covariances were obtained, one could say that the items were conceptualised in a fairly similar way (see items 2.1 and 2.2; items 3.1 and 3.2), even if they aimed to address professional agency at different levels (i.e. in the unit and in the work community). Overall, the fit of the model improved as a result of these modifications. However, because the process of modifying the model on the basis of MIs is data-driven, it is susceptible to the capitalisation of idiosyncratic characteristics within our data (MacCallum et 
al. 1992). Thus, the modifications conducted may not be generalisable to samples obtained from different work contexts or different countries. Considerations of this kind underline the need for further research to validate the dimensions of professional agency, and to confirm the items that apply to them. For this purpose, there will be a need to collect data from different countries and professions, and to include also less educated participants. One should also bear in mind that the items were developed and presented in Finnish, meaning that up to now, only Finnish items have been validated.

The response rate of the study was $32 \%$. It is therefore worth considering the backgrounds of the respondents and their motivations for answering. One could speculate that the individuals who were satisfied with their employer or who were generally active at work participated in the study. One could further surmise that those who were dissatisfied with the opportunities for being agentic at work responded in order to affect their work conditions.

Even though the response rate was fairly low, the number of participants in our data was adequate for the statistical analyses conducted in the present study. Furthermore, the respondent profiles were equivalent to the general and domain-specific employee distributions in Finland. However, a limitation of this study lies in its cross-sectional character. Longitudinal studies will be needed to evaluate whether or not the structure of professional agency remains invariant over time (i.e. with the construct of professional agency having a stable meaning). Professional agency does indeed appear to be a developmental process (Priestley et al. 2012; Vähäsantanen et al. 2009). Thus, the extent to which a person experiences and expresses certain dimensions of professional agency can vary in time, and over different contexts. This suggests that within a longitudinal project, the instrument could be used to reveal changes in the dimensions of professional agency over time, within a given work organisation. Hence, if this kind of investigation were conducted (for example) in education and training settings, it would be possible to reveal the impact of education and 
training for the enhancement of professional agency. Finally, the availability of longitudinal data would make it possible to examine whether the agency dimensions are able to predict work-related outcomes in the future (i.e. whether they have predictive validity). For example, it may be that a strong sense of professional agency is related to individuals' future intentions and actions, including turnover intentions.

This study revealed the structure of professional agency on three specific dimensions. However, future research could explore how individual and social backgrounds (including the work organisation, age, and a supervisory position) are related to the dimensions revealed. In fact, previous studies have shown that individual backgrounds (encompassing work experience, professional goals) and social conditions (e.g. leadership practices, material circumstances) are indeed related to professional agency (Imants et al. 2013; Lukic et al. 2013; Philpott and Oates 2017; Priestley et al. 2012). Although the present study revealed a certain structure for professional agency, its dimensions may well exist variously in different contexts. Arguing along similar lines, Tynjälä (2013) suggests that comparative analyses between different professions or fields of work could detect critical social characteristics peculiar to specific domains.

The present study is in line with the theoretical notion that professional agency refers to proactive and development-oriented activities. Although agency can also be understood to take the form of resistance - as pointed out by a number of authors (e.g. Priestley et al. 2012; Toom et al. 2015) - this perspective was not covered in our measurement instrument. In addition, our instrument covered agency as an individual phenomenon. However, it should be remembered that agency is also a collective phenomenon; thus, it can be understood to include collective activities aimed at influencing shared matters and negotiating collective professional identity (Haapasaari et al. 2016; Hökkä et al. 2017). 
Our measurement instrument (i.e. the instrument addressing three dimensions of professional agency via 17 items) could also work as a practical instrument for work organisations that seek information on professionals' opportunities to enact their agency in different areas, since the measurement offers a nuanced understanding of the relative salience of different dimensions. From this kind of information, it would be possible to focus support on particular areas related to professional agency in the developmental work of organisations. Professional agency can be promoted in socio-cultural contexts through a variety of workrelated training interventions (Haapasaari et al. 2016; Vähäsantanen et al. 2017a, b). One could also say that through efforts to promote professional agency it may be possible to enhance learning at work, and to create a worthwhile space for meaningful work, since this and previous studies have shown professional agency to be connected to these work-related phenomena.

Several scholars have emphasised the crucial importance of professional agency in professionals' learning (see Goller and Paloniemi 2017; Harteis and Goller 2014; Tynjälä 2013). Here, we have revealed the multidimensional structure of professional agency and provided some empirical evidence on the connection between professional agency and learning at work. However, the questionnaire included only a few items related to learning at work, since our main aim was not to investigate learning at work per se, but merely to use the construct in validating the structure of professional learning. Hence, we would emphasise the need for further evidence regarding the relationship between professional agency and learning. In cases of quantitative research, this kind of investigation could include a combination of tested and validated measurements applicable to both professional agency and learning at work.

Some scholars have further emphasised that the constructs of professional agency and job crafting (introduced by Wrzesniewski and Dutton 2001) can be seen as closely connected, 
and even as overlapping (Fuller and Unwin 2017; Goller 2017). The present study could not address this relationship; hence, future research might examine in more detail the connection between job crafting and professional agency. Furthermore, the concepts of proactive behaviour and agency can be seen as closely connected (see Goller and Harteis 2017; Goller and Paloniemi 2017), and future studies could usefully investigate this connection. More broadly, in seeking to test the convergent and discriminant validity of the measurement instrument presented, future research would be well advised to employ other constructs and scales related to professional agency, such as human agency at work (Goller 2017), the proactive personality scale (Bateman and Crant 1993), and self-directed learning (Raemdonck et al. 2017).

\section{Acknowledgements}

This work was supported by the Academy of Finland under Grant number 288925 [The Role of Emotions in Agentic Learning at Work]. The original items and instructions in Finnish are available from the first author on request. We wish to thank the anonymous reviewers for comments and suggestions that greatly improved the article. Our warm thanks go also to Donald Adamson for polishing the language of the article.

\section{References}

Alasoini, T. (2011). Workplace development as part of broad-based innovation policy: Exploiting and exploring three types of knowledge. Nordic Journal of Working Life Studies, 1(1), 23-43.

Asparouhov, T., \& Muthén, B. (2009). Exploratory structural equation modeling. Structural Equation Modeling, 16, 397-438.

Barsade, S. G., \& Gibson, D. E. (2007). Why does affect matter in organizations? Academy of Management Perspectives, 21, 36-59.

Bateman, T. S., \& Crant, J. M. (1993). The proactive component of organizational behavior: A measure and correlates. Journal of Organizational Behavior, 14(2), 103-118.

Billett, S. (2004). Workplace participatory practices: Conceptualising workplaces as learning environments. Journal of Workplace Learning, 16(6), 312-324. 
Billett, S. (2008). Learning through work: Exploring instances of relational interdependencies. International Journal of Educational Research, 47(4), 32-47.

Billett, S. (2011). Subjectivity, self and personal agency in learning through and for work. In M. Malloch, L. Cairns, L. Evans, \& B. O’Connor (Eds.), SAGE handbook of workplace learning (pp. 60-72). Sage: London.

Billett, S., Harteis, C., \& Eteläpelto, A. (Eds.) (2008). Emerging perspectives of workplace learning. Rotterdam: Sense.

Brown, A. (2004). Engineering identities. Career Development International, 9(3), 245-273.

Brown, A., Kirpal, S., \& Rauner, F. (Eds.) (2007). Identities at work. Dordrecht: Springer.

Cattell, R. B. (1966). The scree test for the number of factors. Multivariate Behavioral Research, 1(2), 245-276.

Chalofsky, N. (2003). An emerging construct for meaningful work. Human Resource Development International, 6(1), 69-83.

Chen, F. F. (2007). Sensitivity of goodness of Fit indexes to lack of measurement. Structural Equation Modeling, 14, 464-504.

Cheung, G. W., \& Rensvold, R. B. (2002). Evaluating goodness-of Fit indexes for testing measurement invariance. Structural Equation Modeling, 9, 233-255.

Clore, G. L., \& Huntsinger, J. R. (2007). How emotions inform judgement and regulate thought. Trends in Cognitive Science, 11(9), 393-399.

Collin, K., Lemmetty, S. Herranen, S., Paloniemi, S. Sintonen, T., \& Riivari, E. (2017). Professional agency and creativity in information technology work. In M. Goller, \& S. Paloniemi (Eds.), Agency at work: An agentic perspective on professional learning and development (pp. 249-270). Cham: Springer.

Collin, K., Paloniemi, S., \& Vähäsantanen, K. (2015). Multiple forms of professional agency for (non)crafting of work practices in hospital organisation. Nordic Journal of Working Life Studies, 5(3), 63-83.

Damsa, C. I., Froehlich, D. E., \& Gegenfurtner, A. (2017). Reflections on empirical and methodological accounts of agency at work. In M. Goller, \& S. Paloniemi (Eds.), Agency at work: An agentic perspective on professional learning and development (pp. 445-464). Cham: Springer.

Eraut, M. (2011). How researching learning at work can lead to tools for enhancing learning. In M. Malloch, L. Cairns, L. Evans, \& B. O'Connor (Eds.), SAGE handbook of workplace learning (pp. 181-197). London: Sage. 
Eteläpelto, A., Vähäsantanen, K., Hökkä, P., \& Paloniemi, S. (2013). What is agency? Conceptualizing professional agency at work. Educational Research Review, 10, 4565.

Eteläpelto, A., Vähäsantanen, K., Hökkä, P., \& Paloniemi, S. (2014). Identity and agency in professional learning. In S. Billett, C. Harteis, \& H. Gruber (Eds.), International handbook of research in professional and practice-based learning (pp. 645-672). Dordrecht: Springer.

Fabrigar, L. R., Wegener, D. T., MacCallum, R. C., \& Strahan, E. J. (1999). Evaluating the use of exploratory factor analysis in psychological research. Psychological Methods, 4(3), 272-299.

Fornell, C., \& Larcker, D. F. (1981). Evaluating structural equation models with unobservable variables and measurement error. Journal of Marketing Research, 18(1), 39-50.

Fuller, A., \& Unwin, L. (2017). Job crafting and identity in low-grade work: How hospital porters redefine the value of their work and expertise. Vocations and Learning, 10(3), $307-324$

Goller, M. (2017). Human agency at work: An active approach towards expertise development. Wiesbaden: Springer VS.

Goller, M., \& Harteis, C. (2017). Human agency at work: Towards a clarification and operationalisation of the concept. In M. Goller, \& S. Paloniemi (Eds.), Agency at work: An agentic perspective on professional learning and development (pp. 85-104). Cham: Springer.

Goller, M., \& Paloniemi, S. (Eds.) (2017). Agency at work: An agentic perspective on professional learning and development. Cham: Springer.

Gorsuch, R. L. (1983). Factor analysis. 2nd ed. Hillsdale, NJ: Erlbaum.

Haapasaari, A., Engeström, Y., \& Kerosuo, H. (2016). The emergence of learners' transformative agency in a change laboratory intervention. Journal of Education and Work, 29(2), 232-262.

Harteis, C., \& Goller, M. (2014). New skills for new jobs: Work agency as a necessary condition for successful lifelong learning. In S. Billett, T. Halttunen, \& M. Koivisto (Eds.), Promoting, assessing, recognizing and certifying lifelong learning: International perspectives and practices (pp. 37-56). Dordrecht: Springer.

Hodkinson, P., Biesta, G., \& James, D. (2008). Understanding learning culturally: Overcoming the dualism between social and individual views of learning. Vocations and Learning, 1(1), 27-47. 
Hu, L. T., \& Bentler, P. M. (1999). Cutoff criteria for Fit indexes in covariance structure analysis: Conventional criteria versus new alternatives. Structural Equation Modeling, $6,1-55$.

Hökkä, P., Eteläpelto, A., \& Rasku-Puttonen, H. (2010). Recent tensions and challenges of teacher education as manifested in the curriculum discourse. Teaching and Teacher Education, 26(4), 845-885.

Hökkä, P., Eteläpelto, A., \& Rasku-Puttonen, H. (2012). The professional agency of teacher educators amid academic discourses. Journal of Education for Teaching, 38(1), 83102.

Hökkä, P., Rasku-Puttonen, H., \& Eteläpelto, A. (2008). Teacher educators’ workplace learning: The interdependency between individual agency and social context. In S. Billett, C. Harteis, \& A. Eteläpelto (Eds.), Emerging perspectives of workplace learning (pp. 51-65). Rotterdam: Sense Publishers.

Hökkä, P., Vähäsantanen, K., \& Mahlakaarto, S. (2017). Teacher educators' collective professional agency and identity - Transforming marginality to strength. Teaching and Teacher Education, 63, 36-46.

Imants, J., Wubbels, T., \& Vermunt, J. (2013). Teachers' enactment of workplace conditions and their beliefs and attitudes toward reform. Vocations and Learning, 6(3), 323-346.

Jääskelä, P., \& Valleala, U. M. (2012). Opiskelijoiden toimijuus yliopisto-opinnoissa: Valtasuhteita, osallistumisaktiivisuutta, tietojen ja taitojen hallintaa. [University students' agency: Power relations, participation activity, knowledge and skills Competences.] Paper presented at the symposium of Interactive Teaching and Learning, Jyväskylä, February 23.

Kaiser, H. F. (1960). The application of electronic computers to factor analysis. Educational and Psychological Measurement, 20, 141-151.

Ketelaar, E., Beijaard, D., Boshuizen, H. P. A., \& den Brok, J. (2012). Teachers' positioning towards an educational innovation in the light of ownership, sense-making and agency. Teaching and Teacher Education, 28(2), 273-282.

Kira, M., \& Balkin, D. (2014). Interactions between work and identities: Thriving, withering, or redefining the self? Human Resource Management Review, 24(2), 131-143.

Kline, R. B. (2016). Principles and practice of structural equation modeling (4th ed). New York: Guilford Press. 
Lave, J. (1993). The practice of learning. In S. Chaiklin, \& J. Lave (Eds.), Understanding practice: Perspectives on activity and context (pp. 3-32). Cambridge: Cambridge University Press.

Lehto, A-M., \& Sutela, H. (2014). Työolojen muutokset 1977-2013. [Changes in working conditions 1977-2013]. Official Statistics of Finland. Helsinki: Statistics Finland.

Lipponen, L., \& Kumpulainen, K. (2011). Acting as accountable authors: Creating interactional spaces for agency work in teacher education. Teaching and Teacher Education, 27(5), 812-819.

Lukic, D., Margaryan, A., \& Littlejohn, A. (2013). Individual agency in learning from incidents. Human Resource Development International, 16(4), 409-425.

Marsh, H. W., Hau, K.-T., \& Grayson, D. (2005). Goodness of Fit evaluation. In A. Maydeu Olivares, \& J. McArdle (Eds.), Contemporary psychometrics (pp. 275-340). Mahwah NJ: Erlbaum.

Marsh, H. W., Lüdtke, O., Muthén, B., Asparouhov, T. Morin, A. J. S., Trautwein, U., \& Nagengast, B. (2010). A new look at the Big Five factor structure through exploratory structural equation modeling. Psychological Assessment, 22, 471-491.

Marsh, H. W., Lüdtke, O. Nagengast, B., \& Morin, A. J. S. (2013). Why item parcels are (almost) never appropriate: Two wrongs do not make a right - Camouflaging misspecification with item parcels in CFA models. Psychological Methods, 18, 257284.

Marsh, H. W., Muthén, B., Asparouhov, T., Lüdtke, O., Robitzsch, A., Morin, A. J. S., \& Trautwein, U. (2009). Exploratory structural equation modeling, integrating CFA and EFA: Application to students' evaluations of university teaching. Structural Equation Modeling, 16, 439-476.

Meredith, W. (1993). Measurement invariance, factor analysis and factorial invariance. Psychometrika, 58, 525-543.

Muthén, L. K., \& Muthén, B. (1998-2012). Mplus user's guide. Los Angeles, CA: Muthén \& Muthén.

Paloniemi, S., \& Goller, M. (2017). The multifaceted nature of agency and professional learning. In M. Goller, \& S. Paloniemi (Eds.), Agency at work: An agentic perspective on professional learning and development (pp. 465-478). Cham: Springer.

Philpott, C., \& Oates, C. (2017). Teacher agency and professional learning communities: What can learning rounds in Scotland teach us? Professional Development in Education, 43(3), 318-333. 
Priestley, M., Edwards, R., Priestley, A., \& Miller, K. (2012). Teacher agency in curriculum making: Agents of change and spaces for manoeuvre. Curriculum Inquiry, 42(2), 191214.

Pyhältö, K., Pietarinen, J., \& Soini, T. (2012). Do comprehensive school teachers perceive themselves as active professional agents in school reforms? Journal of Educational Change, 13(1), 95-116.

Pyhältö, K., Pietarinen, J., \& Soini, T. (2015). Teachers' professional agency and learning From adaption to active modification in the teacher community. Teaching and Teachers: Theory and Practice, 21(7), 811-830.

Raemdonck, I., Thijssen, J., \& de Greef, M. (2017). Self-directedness in work-related learning processes. Theoretical perspectives and development of a measurement instrument. In M. Goller, \& S. Paloniemi (Eds.), Agency at work. Agentic perspective on professional learning and development (pp. 401-423). Cham: Springer.

Raykov, T. (2004). Behavioral scale reliability and measurement invariance evaluation using latent variable modeling. Behavioral Therapy, 35(2), 299-311.

Ruohotie-Lyhty, M., \& Moate, J. (2016). Who and how? Preservice teachers as active agents developing professional identities. Teaching and Teacher Education, 55, (4), 318327.

Satorra, A., \& Bentler, P. (1999). A scaled difference chi-square test statistic for moment structure analysis. Technical report. Los Angeles: University of California.

Smith, R. (2012). Clarifying the subject centred approach to vocational learning theory: Negotiated participation. Studies in Continuing Education, 34(2), 159-174.

Tabachnik, B. G., \& Fidell, L. S. (2001). Using multivariate statistics. Boston: Allyn and Bacon.

Thrash, T. M., \& Elliot, A. (2003). Inspiration as a psychological construct. Journal of Personality and Social Psychology, 84(4), 871-889.

Tomlinson, J., Muzio, D., Sommerlad, H., Webley, L., \& Duff, L. (2013). Structure, agency and career strategies of white women and black and minority ethnic individuals in the legal profession. Human Relations, 66(2), 245-269.

Toom, A., Pyhältö, K., \& Rust, F. O. (2015). Teachers’ professional agency in contradictory times. Teachers and Teaching: Theory and Practice, 21(6), 615-623.

Tynjälä, P. (2008). Perspectives into learning at the workplace. Educational Research Review, 3(2), 130-154. 
Tynjälä, P. (2013). Toward a 3-P model of workplace learning: A literature review. Vocations and Learning, 6(1), 11-36.

Valleala, U., Herranen, S., Collin, K., \& Paloniemi, S. (2015). Fostering learning opportunities through employee participation amid organizational change. Vocations and Learning, 8(1), 1-34.

Velicer, W. F. (1976). Determining the number of components from matrix of partial correlations. Psychometrika, 41(3), 321-327.

Virkkunen, J. (2006). Dilemmas in building shared transformative agency. Activités, 3(1), 1942.

Vuori, T., San, E., \& Kira, M. (2012). Meaningfulness-making at work. Qualitative Research in Organizations and Management: An International Journal, 7(2), 231-248.

Vähäsantanen, K., \& Eteläpelto, A. (2011). Vocational teachers' pathways in the course of a curriculum reform. Journal of Curriculum Studies, 43(3), 291-312.

Vähäsantanen, K., \& Eteläpelto, A. (2015). Professional agency, identity, and emotions while leaving one's work organization. Professions and Professionalism, 5(3), 1-16.

Vähäsantanen, K., Hökkä, P., Eteläpelto, A., Rasku-Puttonen, H., \& Littleton, K. (2008). Teachers' professional identity negotiations in two different work organisations. Vocations and Learning, 1(2), 131-148.

Vähäsantanen, K., Hökkä, P., Paloniemi, S., Herranen, S., \& Eteläpelto, A. (2017a). Professional learning and agency in an identity coaching programme. Professional Development in Education, 43(4), 514-536.

Vähäsantanen, K., Paloniemi, S., Hökkä, P., \& Eteläpelto, A. (2017b). An agency-promoting learning arena for developing shared work practices. In M. Goller, \& S. Paloniemi (Eds.), Agency at work: An agentic perspective on professional learning and development (pp. 351-372). Cham: Springer.

Vähäsantanen, K., Saarinen, J., \& Eteläpelto, A. (2009). Between school and working life: Vocational teachers' agency in boundary-crossing settings. International Journal of Educational Research, 48(6), 395-404.

Weber, S. (2013). Sense of workplace learning. Vocations and Learning, 6(1), 1-9.

Wrzesniewski, A., \& Dutton, J. E. (2001). Crafting a job: Revisioning employees as active crafters of their work. Academy of Management Review, 26(2), 179-201.

Ylén, M. (2017). Professional virtues and agency in work: Ethnography of software developers. In M. Goller, \& S. Paloniemi (Eds.), Agency at work: An agentic perspective on professional learning and development (pp. 291-310). Cham: Springer. 
Young, V., \& Bhaumik, C. (2011). Health and well-being at work: A survey of employees.

Department for Work and Pensions. Research Report 751. Sheffield, UK. 
Table 1. Proposed dimensions of professional agency, using 22 items (initial assumption).

\begin{tabular}{|c|c|}
\hline $\begin{array}{l}\text { Dimensions } \\
\text { (utilised references) }\end{array}$ & Items \\
\hline $\begin{array}{l}\text { Decision Making at Work } \\
\text { (e.g. Billett 2008; Ketelaar et al. } \\
\text { 2012; Vähäsantanen et al. 2008) }\end{array}$ & $\begin{array}{l}\text { 1.1. I can participate in the preparation of matters in my unit. } \\
\text { 1.2. I can make decisions regarding my own work. } \\
\text { 1.3. I can participate in the decision making in my unit. } \\
\text { 1.4. I can influence the equal division of work in the work } \\
\text { community }\end{array}$ \\
\hline $\begin{array}{l}\text { Being Heard at Work } \\
\text { (e.g. Pyhältö et al. 2012) }\end{array}$ & $\begin{array}{l}\text { 2.1. My opinion is taken into consideration in my unit. } \\
\text { 2.2. My views are taken into consideration in the work community. } \\
\text { 2.3. I am heard in matters relating to my own work. }\end{array}$ \\
\hline $\begin{array}{l}\text { Participation in Shared Work } \\
\text { Practices } \\
\text { (e.g. Billett 2004; Hökkä et al. 2012) }\end{array}$ & $\begin{array}{l}\text { 3.1. I ask or comment actively in my unit. } \\
\text { 3.2. I actively bring up my own opinions in the work community. } \\
\text { 3.3. I actively collaborate with others in my unit. } \\
\text { 3.4. I take part in the development of my unit's actions. }\end{array}$ \\
\hline $\begin{array}{l}\text { Transforming Work } \\
\text { Practices } \\
\text { (e.g. Billett 2011; Virkkunen 2006) }\end{array}$ & $\begin{array}{l}\text { 4.1. I develop my ways of working. } \\
\text { 4.2. From time to time I raise questions about some of the working } \\
\text { methods in the work community } \\
\text { 4.3. I make developmental suggestions regarding collective work } \\
\text { practices. } \\
\text { 4.4. I try out new ideas in my work. } \\
\text { 4.5. I put forward developmental suggestions related to my work. }\end{array}$ \\
\hline $\begin{array}{l}\text { Negotiating Professional } \\
\text { Identity } \\
\text { (e.g. Brown et al. 2007; Ketelaar et } \\
\text { al. 2012; Vähäsantanen et al. 2008) }\end{array}$ & $\begin{array}{l}\text { 5.1. I can act according to my ethical principles in my job. } \\
\text { 5.2. I can act according to my own values in my work. } \\
\text { 5.3. I can realise my professional goals in my work. } \\
\text { 5.4. In my work I can focus on things that interest me. }\end{array}$ \\
\hline $\begin{array}{l}\text { Constructing a Professional } \\
\text { Career } \\
\text { (e.g. Brown 2004) }\end{array}$ & $\begin{array}{l}\text { 6.1. I have the possibility to advance my career in this organisation. } \\
6.2 \text {. I can advance my career in my work. }\end{array}$ \\
\hline
\end{tabular}

Note. A 5-point response scale: 1 = I strongly disagree... 5 = I strongly agree. 
Table 2. EFA results based on dataset $1(n=235)$. Principal axis factoring was used as the method of extraction, and promax as the method of rotation.

\begin{tabular}{|c|c|c|c|c|}
\hline \multirow[t]{2}{*}{ Items $^{\mathrm{a}}$} & \multicolumn{3}{|c|}{ Loadings } & \multirow[t]{2}{*}{ Communalities } \\
\hline & $\begin{array}{c}\mathrm{F} 1 \\
\text { Influencing at work }\end{array}$ & $\begin{array}{c}\mathrm{F} 2 \\
\text { Developing Work Practices }\end{array}$ & $\begin{array}{c}\mathrm{F} 3 \\
\text { Negotiating Professional Identity }\end{array}$ & \\
\hline 1.1. I can participate in the preparation of matters in my unit. & .785 & .078 & .029 & 0.716 \\
\hline 1.2. I can make decisions regarding my own work. & .318 & -.037 & .503 & 0.519 \\
\hline 1.3. I can participate in the decision making in my unit. & .759 & .069 & -.051 & 0.588 \\
\hline 2.1. My opinion is taken into consideration in my unit. & .602 & .023 & .250 & 0.621 \\
\hline 2.2. My views are taken into consideration in the work community. & .577 & -.051 & .348 & 0.751 \\
\hline 2.3. I am heard in matters relating to my own work. & .498 & -.091 & .440 & 0.631 \\
\hline 3.1. I ask or comment actively in my unit. & .236 & .673 & -.138 & 0.578 \\
\hline 3.2. I actively bring up my own opinions in the work community. & .157 & .666 & -.034 & 0.552 \\
\hline 3.3. I actively collaborate with others in my unit. & .248 & .559 & -.112 & 0.446 \\
\hline 3.4. I take part in the development of my unit's actions. & .442 & .448 & -.036 & 0.568 \\
\hline 4.1. I develop my ways of working. & -.247 & .603 & .306 & 0.423 \\
\hline 4.3. I make developmental suggestions regarding collective work practices. & -.024 & .814 & -.126 & 0.580 \\
\hline 4.4. I try out new ideas in my work. & -.227 & .543 & .486 & 0.535 \\
\hline 5.2. I can act according to my own values in my work. & .087 & .003 & .595 & 0.424 \\
\hline 5.3. I can realise my professional goals in my work. & .155 & -.012 & .702 & 0.637 \\
\hline 5.4. In my work, I can focus on things that interest me. & -.091 & .022 & .781 & 0.546 \\
\hline 6.2. I can advance my career in my work. & .053 & -.092 & .641 & 0.411 \\
\hline$\%$ of variance explained by factor & 4.82 & 10.02 & 40.60 & \\
\hline Composite reliability for the factor & 0.769 & 0.813 & 0.776 & \\
\hline
\end{tabular}

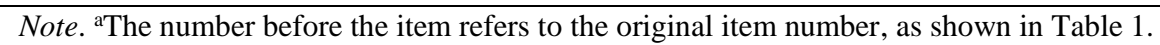


Table 3. ESEM results (datasets 2 and 3, $n=354$ ): three dimensions of professional agency, based on 17 items.

\begin{tabular}{|c|c|c|c|c|}
\hline \multirow[t]{2}{*}{ Items $^{\mathrm{a}}$} & \multicolumn{3}{|c|}{ Standardised loadings } & \multirow{2}{*}{$\begin{array}{l}\text { Residual } \\
\text { variances }\end{array}$} \\
\hline & $\begin{array}{c}\mathrm{F} 1 \\
\text { Influencing } \\
\text { at Work } \\
\end{array}$ & $\begin{array}{c}\mathrm{F} 2 \\
\text { Developing Work } \\
\text { Practices }\end{array}$ & $\begin{array}{c}\text { F3 } \\
\text { Negotiating } \\
\text { Professional Identity }\end{array}$ & \\
\hline 1.1. I can participate in the preparation of matters in my unit. & $.80 * * *$ & $.09 *$ & .07 & $.23 * * *$ \\
\hline 1.2. I can make decisions regarding my own work. & $.58 * * *$ & .06 & $.20 *$ & $.47 * * *$ \\
\hline 1.3. I can participate in the decision making in my unit. & $.74 * * *$ & $.13^{*}$ & .06 & $.31 * * *$ \\
\hline 2.1. My opinion is taken into consideration in my unit. & $.57 * * *$ & .07 & $.18^{*}$ & $.49 * * *$ \\
\hline 2.2. My views are taken into consideration in the work community. & $.43 * * *$ & .07 & $.32 * * *$ & $.53 * * *$ \\
\hline 2.3. I am heard in matters relating to my own work. & $.52 * * *$ & -.01 & $.38 * * *$ & $.37 * * *$ \\
\hline 3.1. I ask or comment actively in my unit. & .04 & $.57 * * *$ & .07 & $.63 * * *$ \\
\hline 3.2. I actively bring up my own opinions in the work community. & .08 & $.64 * * *$ & .04 & $.53 * * *$ \\
\hline 3.3. I actively collaborate with others in my unit. & $.20^{*}$ & $.55 * * *$ & .14 & $.49 * * *$ \\
\hline 3.4. I take part in the development of my unit's actions. & $.27 * * *$ & $.62 * * *$ & .02 & $.41 * * *$ \\
\hline 4.1. I develop my ways of working. & .00 & $.55 * * *$ & $.34 * * *$ & $.46^{* * *}$ \\
\hline 4.3. I make developmental suggestions regarding collective work practices. & .04 & $.67 * * *$ & -.08 & $.56^{* * *}$ \\
\hline 4.4. I try out new ideas in my work. & .03 & $.50 * * *$ & $.30 * *$ & $.55^{* * *}$ \\
\hline 5.2. I can act according to my own values in my work. & $.19 *$ & .10 & $.45 * * *$ & $.61 * * *$ \\
\hline 5.3. I can realise my professional goals in my work. & .05 & .05 & $.72 * * *$ & $.41 * * *$ \\
\hline 5.4. In my work I can focus on things that interest me. & .10 & $.10^{*}$ & $.72 * * *$ & $.34 * * *$ \\
\hline 6.2. I can advance my career in my work. & $.17 * *$ & -.07 & $.73 * * *$ & $.49 * * *$ \\
\hline
\end{tabular}

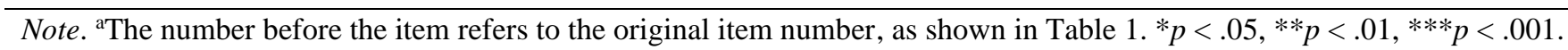


Table 4. Composite reliabilities for the dimension of professional agency; plus correlations, average variance extracted (AVE), and estimated amount of shared variance between all the factors examined.

\begin{tabular}{|c|c|c|c|c|c|c|}
\hline Factors & $\begin{array}{l}\text { Composite reliability score on } \\
\text { the dimension of Professional } \\
\text { agency }^{\mathrm{a}}\end{array}$ & 1 & 2 & 3 & 4 & 5 \\
\hline 1 Influencing at Work & 0.75 & 0.38 & 0.12 & 0.29 & 0.32 & 0.32 \\
\hline 2 Developing Work Practices & 0.74 & $0.35 * * *$ & 0.34 & 0.11 & 0.25 & 0.08 \\
\hline 3 Negotiating Professional Identity & 0.75 & $0.54 * * *$ & $0.33 * * *$ & 0.44 & 0.30 & 0.64 \\
\hline 4 Learning at Work & - & $0.57 * * *$ & $0.50 * * *$ & $0.55 * * *$ & 0.54 & 0.40 \\
\hline 5 Emotionally Meaningful Work & - & $0.55^{* * *}$ & $0.29 * * *$ & $0.80 * * *$ & $0.63 * * *$ & 0.65 \\
\hline
\end{tabular}

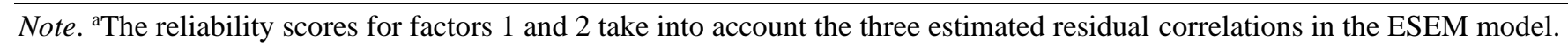

Correlations between the factors are below the diagonal, shared variance (i.e. squared factor correlations) are above the diagonal, and AVE estimates are presented on the diagonal (in bold). $* * * p<0.001$. 
Table 5. Fit indices from the tests of measurement invariance across datasets 2 and $3(n=354)$.

\begin{tabular}{|c|c|c|c|c|c|c|c|c|}
\hline \multicolumn{2}{|c|}{ Invariance step } & \multirow{2}{*}{$\begin{array}{l}\chi^{2}(d f) \\
285.86\end{array}$} & \multirow{2}{*}{$\begin{array}{l}d f \\
170\end{array}$} & \multirow{2}{*}{$\begin{array}{c}\begin{array}{c}\text { Scaling } \\
\text { correction }\end{array} \\
1.13\end{array}$} & \multirow{2}{*}{$\begin{array}{c}\chi^{2} \text { difference test } \\
\chi^{2}(d f)^{\mathrm{a}} \\
-\end{array}$} & \multirow{2}{*}{$\begin{array}{l}C F I \\
0.95\end{array}$} & \multirow{2}{*}{$\begin{array}{c}T L I \\
0.93\end{array}$} & \multirow{2}{*}{$\begin{array}{c}\text { RMSEA } \\
(90 \% C I)\end{array}$} \\
\hline 1 & None (configural invariance) & & & & & & & \\
\hline 2 & Loadings (weak invariance) & 349.34 & 212 & 1.19 & $\begin{array}{l}\text { model } 2 \text { vs. } 1 \\
64.69(42)^{*}\end{array}$ & 0.95 & 0.93 & $\begin{array}{c}0.06 \\
(0.05 ; 0.07)\end{array}$ \\
\hline $3 \mathrm{p}$. & Loadings, intercepts (p. strong invariance) & 370.05 & 222 & 1.19 & $\begin{array}{l}\text { model 3p. vs. } 2 \\
20.71(10)^{*}\end{array}$ & 0.94 & 0.93 & $\begin{array}{c}0.06 \\
(0.05 ; 0.07)\end{array}$ \\
\hline 4 & $\begin{array}{l}\text { Loadings, intercepts (p.), residual variances (strict } \\
\text { invariance) }\end{array}$ & 455.94 & 242 & 1.19 & $\begin{array}{l}\text { model } 4 \text { vs. } 3 p . \\
85.89(20)^{* * *}\end{array}$ & 0.91 & 0.90 & $\begin{array}{c}0.07 \\
(0.06 ; 0.08)\end{array}$ \\
\hline 6 & $\begin{array}{l}\text { Loadings, intercepts (p.), residual variances (p.), } \\
\text { factor variances \& covariances, factor means }\end{array}$ & 432.28 & 248 & 1.20 & $\begin{array}{l}\text { model } 6 \text { vs. } 5 \\
18.73(3) * * *\end{array}$ & 0.93 & 0.92 & $\begin{array}{c}0.07 \\
(0.06 ; 0.08)\end{array}$ \\
\hline
\end{tabular}

Note. $\mathrm{p} .=$ partial invariance. ${ }^{\mathrm{a}} \mathrm{A}$ reference model fits the data better if $p<.05 .{ }^{\text {n.s. }}$ not statistically significant, ${ }^{*} p<.05, * * p<.01,{ }^{* * * *} p<.001$. 


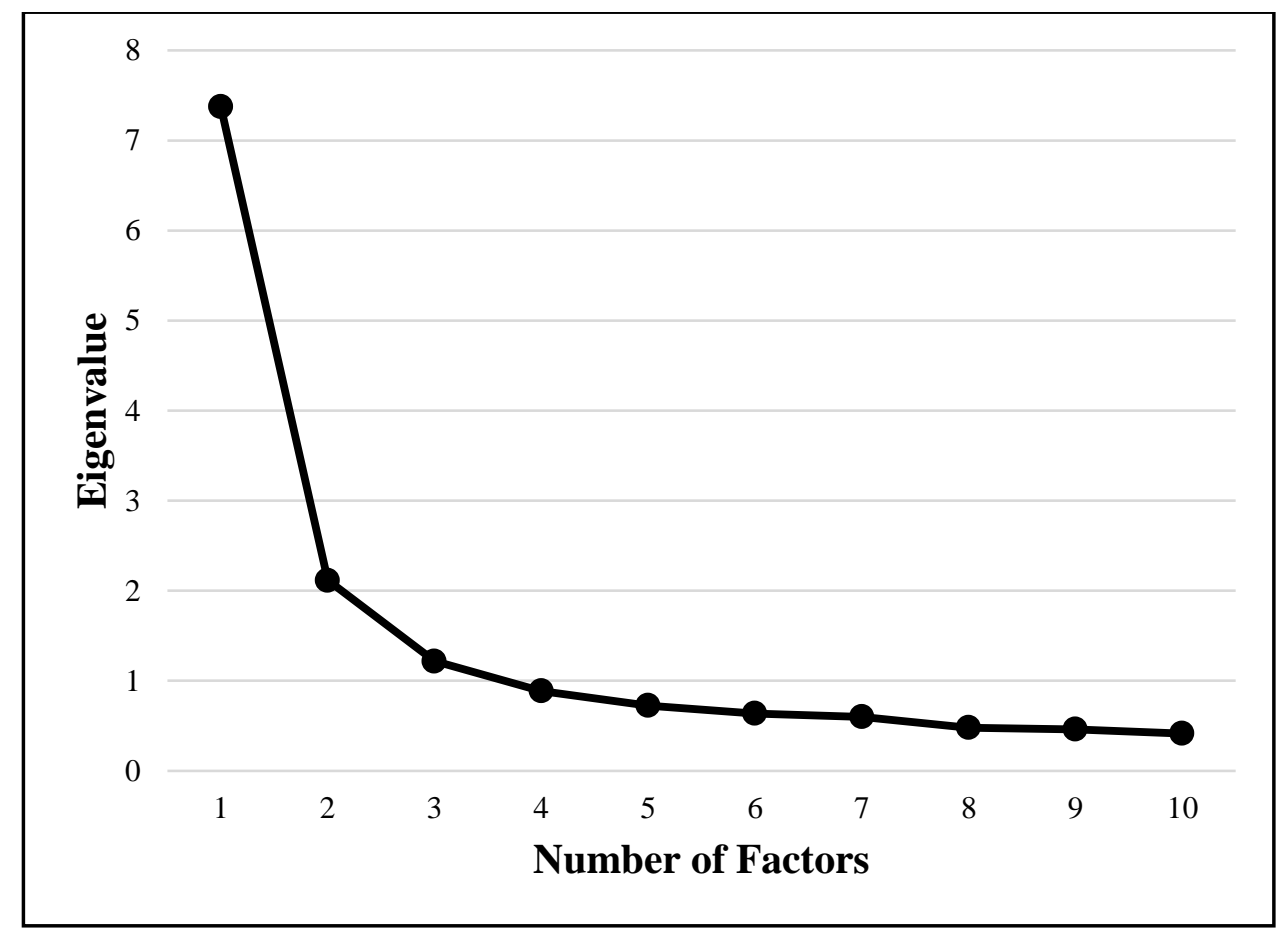

Figure 1a. Scree plot from EFA with PAF extraction based on dataset $1(n=235)$.

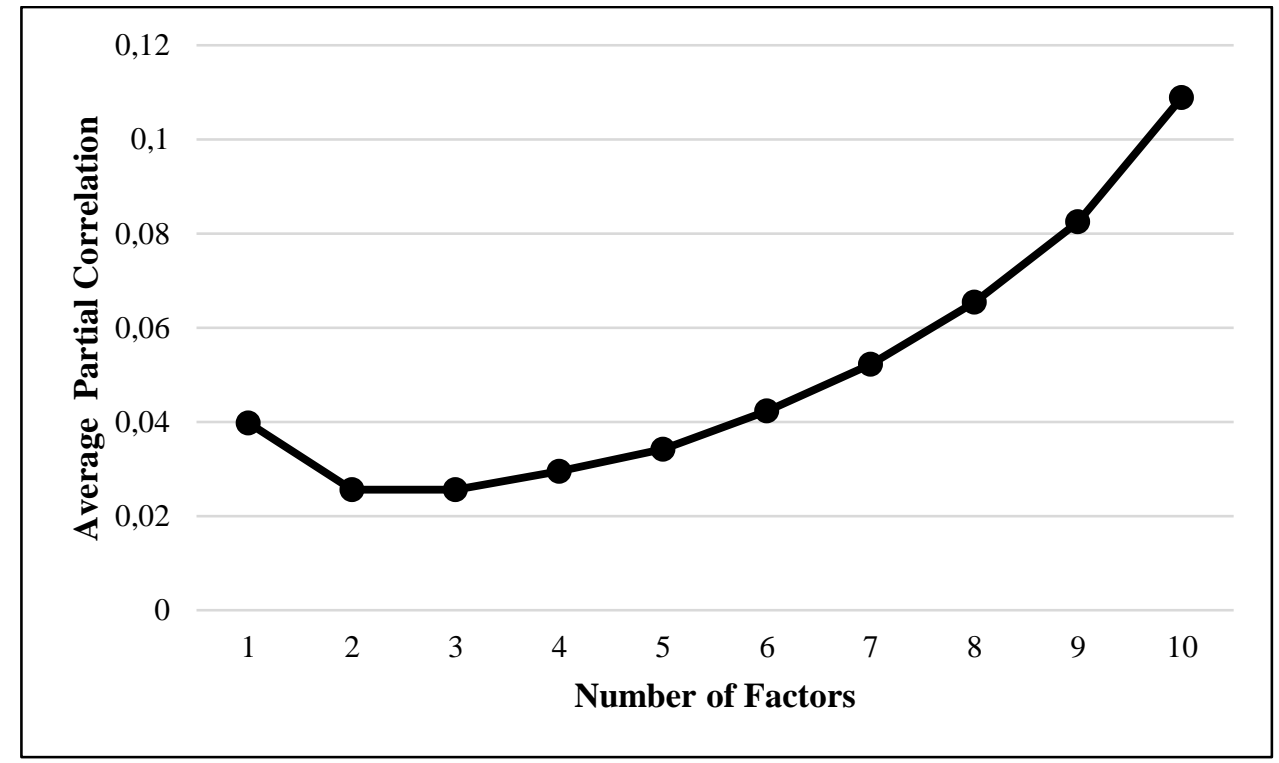

Figure 1b. Average partial correlations (MAP test) based on dataset $1(n=235)$. 


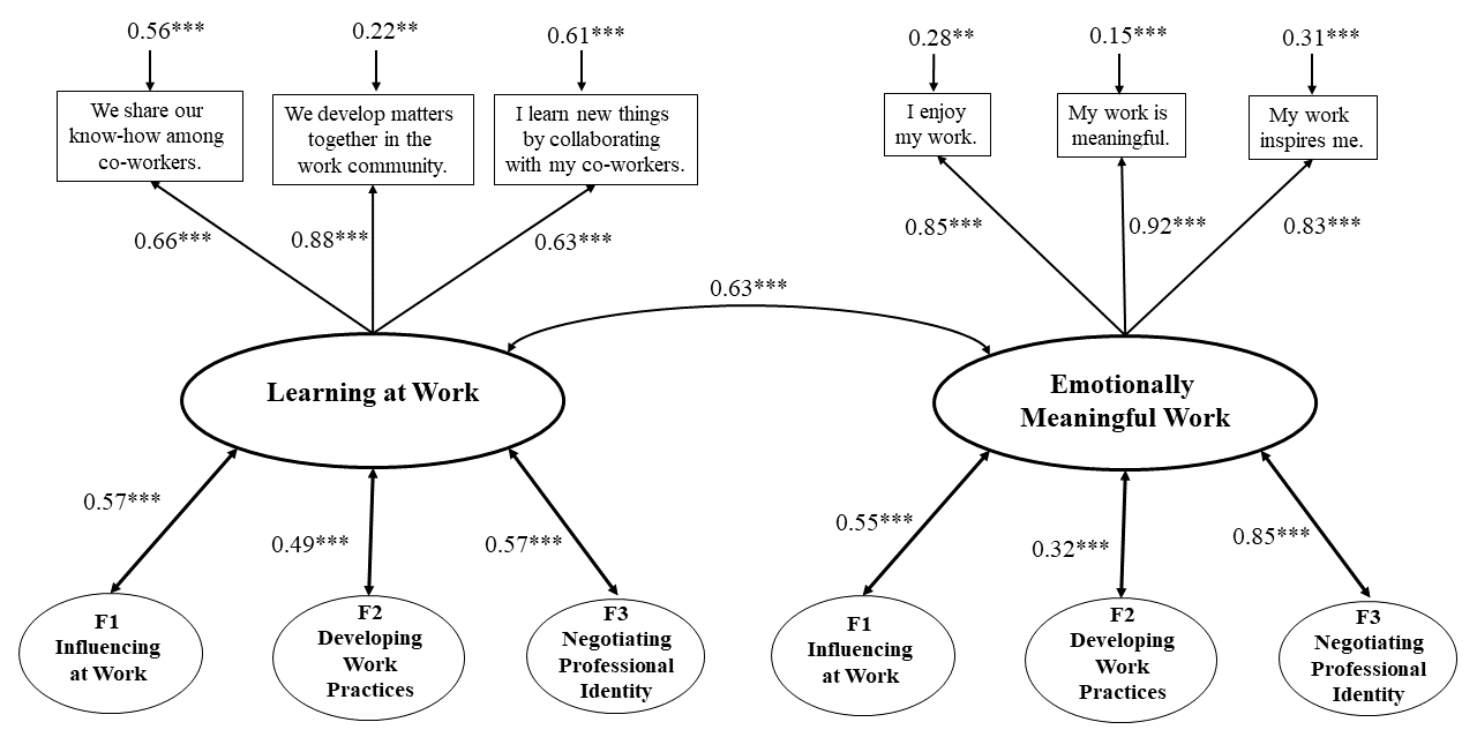

Figure 2. Dimensions of professional agency in relation to Learning at Work and

Emotionally Meaningful Work (dataset 2, $n=261$ ). For the sake of clarity, the manifest indicators of the dimensions of professional agency are not depicted in the Figure. **pvalue $<0.01 ; * * * p$-value $<0.001$. 
Appendix 1. Means $(M)$, standard deviations $(S D)$ and Pearson correlations of the 17 items of professional agency in datasets 2 and $3(N=354)$.

\begin{tabular}{|c|c|c|c|c|c|c|c|c|c|c|c|c|c|c|c|c|c|}
\hline Items $^{a}$ & 1.1. & 1.2 & 1.3. & 2.1 & 2.2 & 2.3 & 3.1 . & 3.2 . & 3.3 . & 3.4 . & 4.1. & 4.3. & 4.4. & 5.2 & 5.3. & 5.4 & 6.2 \\
\hline 1.1. & - & & & & & & & & & & & & & & & & \\
\hline 1.2. & $.62 * * *$ & - & & & & & & & & & & & & & & & \\
\hline 1.3. & $.74 * * *$ & $.62 * * *$ & - & & & & & & & & & & & & & & \\
\hline 2.1 . & $.58 * * *$ & $.51 * * *$ & $.61 * * *$ & - & & & & & & & & & & & & & \\
\hline 2.2 . & $.55^{* * * *}$ & $.54 * * *$ & $.52 * * *$ & $.65 * * *$ & - & & & & & & & & & & & & \\
\hline 2.3 . & $.68 * * *$ & $.61 * * *$ & $.53 * * *$ & $.61 * * *$ & $.62 * * *$ & - & & & & & & & & & & & \\
\hline 3.1 . & $.27 * * *$ & $.25 * * *$ & $.33 * * *$ & $.22 * * *$ & $.30 * * *$ & $.24 * * *$ & - & & & & & & & & & & \\
\hline 3.2 . & $.35^{* * * *}$ & $.31 * * *$ & $.31 * * *$ & $.29 * * *$ & $.33 * * *$ & $.32 * * *$ & $.66^{* * * *}$ & - & & & & & & & & & \\
\hline 3.3 . & $.46^{* * * *}$ & $.36 * * *$ & $.45^{* * * *}$ & $.40 * * *$ & $.34 * * *$ & $.42 * * *$ & $.48 * * *$ & $.49 * * *$ & - & & & & & & & & \\
\hline 3.4 . & $.49 * * *$ & $.35 * * *$ & $.53 * * *$ & $.42 * * *$ & $.35 * * *$ & $.39 * * *$ & $.43 * * *$ & $.47 * * *$ & $.59 * * *$ & - & & & & & & & \\
\hline 4.1 . & $.42 * * *$ & $.36 * * *$ & $.38^{* * * *}$ & $.33 * * *$ & $.37 * * *$ & $.37 * * *$ & $.41 * * *$ & $.43 * * *$ & $.49^{* * *}$ & $.54 * * *$ & - & & & & & & \\
\hline 4.3 . & $.26 * * *$ & $.22 * * *$ & $.25 * * *$ & $.22 * * *$ & $.24 * * *$ & $.17 * *$ & $.40 * * *$ & $.52 * * *$ & $.34 * * *$ & $.46^{* * * *}$ & $.44 * * *$ & - & & & & & \\
\hline 4.4. & $.38 * * *$ & $.44 * * *$ & $.34 * * *$ & $.34 * * *$ & $.35 * * *$ & $.39 * * *$ & $.35^{* * *}$ & $.49 * * *$ & $.44 * * *$ & $.46^{* * *}$ & $.52 * * *$ & $.54 * * *$ & - & & & & \\
\hline 5.2. & $.45 * * *$ & $.40 * * *$ & $.43 * * *$ & $.41 * * *$ & $.46^{* * * *}$ & $.45 * * *$ & $.36 * * *$ & $.29 * * *$ & $.33^{* * * *}$ & $.30 * * *$ & $.40^{* * * *}$ & $.16^{* *}$ & $.24 * * *$ & - & & & \\
\hline 5.3 . & $.43 * * *$ & $.43 * * *$ & $.45^{* * * *}$ & $.44 * * *$ & $.45 * * *$ & $.50 * * *$ & $.25 * * *$ & $.24 * * *$ & $.33 * * *$ & $.31 * * *$ & $.45^{* * * *}$ & $.16^{* *}$ & $.40 * * *$ & $.47 * * *$ & - & & \\
\hline 5.4. & $.50 * * *$ & $.48 * * *$ & $.49 * * *$ & $.43 * * *$ & $.48 * * *$ & $.57 * * *$ & $.26 * * *$ & $.30 * * *$ & $.45^{* * *}$ & $.41 * * *$ & $.44 * * *$ & $.19 * * *$ & $.43^{* * * *}$ & $.51 * * *$ & $.62 * * *$ & - & \\
\hline 6.2 . & $.47 * * *$ & $.35 * * *$ & $.45^{* * *}$ & $.41 * * *$ & $.42 * * *$ & $.53 * * *$ & $.16 * *$ & $.16^{* *}$ & $.28 * * *$ & $.30 * * *$ & $.38^{* * *}$ & .09 & $.32 * * *$ & $.43 * * *$ & $.53 * * *$ & $.58 * * *$ & - \\
\hline$M$ & 3.59 & 3.62 & 3.50 & 3.89 & 3.97 & 3.87 & 3.87 & 3.96 & 4.05 & 3.81 & 3.97 & 3.73 & 3.77 & 4.15 & 3.76 & 3.53 & 3.23 \\
\hline$S D$ & 1.11 & 1.03 & 1.16 & 0.96 & 0.92 & 0.97 & 0.88 & 0.83 & 0.82 & 0.93 & 0.81 & 0.84 & 0.89 & 0.82 & 0.93 & 1.01 & 1.20 \\
\hline
\end{tabular}

Note. ${ }^{a}$ The number before the item refers to the original item number shown in Table $1 .{ }^{* *} p<.01 . * * * p<.001$. Note. A 5 -point response scale: $1=$ I strongly disagree... $5=$ I strongly agree. 
